\title{
SIMILARITIES IN PERIODS OF METEOROLOGICAL VARIABLES OVER KENYA AND SOLAR ACTIVITY PERIODS
}

\author{
J.O.H. Ndeda ${ }^{1}$, A.B. Rabiu ${ }^{2}$, L.H.M. Ngoo $^{3}$, and G.O. Ouma ${ }^{4}$ \\ ${ }^{1}$ Dept. of Physics, Jomo Kenyatta University of Agriculture \& Technology (JKUAT). \\ P.O Box 62000-00200, Nairobi, Kenya. \\ ${ }^{2}$ Space Physics Laboratory, Dept. of Physics, Federal University of Technology, Akure, Nigeria. \\ ${ }^{3}$ Dept. of Electrical Engineering, JKUAT. P.O. Box 62000-00200, Nairobi, Kenya. \\ ${ }^{4}$ Dept. of Meteorology, University of Nairobi. P.O. Box 30197-00100, Nairobi, Kenya.
}

\begin{abstract}
Using the fast Fourier transform (FFT) method, we determined the spectral characteristics of some meteorological variables over Kenya and identified the prominent periodicities associated with the variables. The meteorological variables studied are the maximum temperature, minimum temperature, average temperature, wind speed, precipitation, relative humidity, solar radiation intensity, evaporation and sunshine duration. Data from five terrestrial stations, representing the regional climatic zones in Kenya, were employed in the study. The result reveals periods that are associated with solar activity. It is established that solar forcing is very significant over the Kenyan climate. The Sun-Climate relations were influenced at some locations by local effects such as orography and vegetation.
\end{abstract}

Keywords: periodicity, solar activity, Sun-climate relations

\section{INTRODUCTION}

Many meteorological variables are well known for their periodicities. Many geological records of climatic and environmental change based on various proxy variables exhibit distinct cycles that have been attributed to extraterrestrial forcing (Anderson 1982, Dean 2006). The seasonal effects are more pronounced across the variables. The exact periodicity can be estimated using computing tools. The knowledge about these periodic values help us to know the physical state of the atmosphere responsible. This will in turn serve as a means of predicting, in advance, the hazardous effects the parameters may have on the earth and bio-sphere in general.
In addition the study of the periodic behavior of meteorological variables gives insight into the various mechanisms involved in the different processes responsible for variability of parameters of interest. Whether a particular process is chaotic or harmonic in nature can also be judged from these studies. This present effort investigated the spectra behavior of meteorological variables, include maximum temperature, minimum temperature, average temperature, wind speed, precipitation, relative humidity, solar radiation intensity, evaporation and sunshine duration; obtained from archives of Kenya Meteorological Department (KMD) by subjecting them to fast Fourier transform (FFT). 


\section{Research Methodology}

According to Bai (2003), Valde's-Galicia and Mendoza (2005), Prestes et al. (2006); to study periodicity in a regular time series $X_{j}+X\left(t_{j}\right)$, a series of measurements made at times $t_{j}$ separated by regular intervals, one often uses Fourier spectral analysis. For an irregular time series, Scargle (1982) developed a periodogram calculated by the following equation:

$P_{x} v=\frac{1}{2}\left\{\frac{\left[\sum_{j=1}^{N} X_{j} \cos 2 \pi v t_{j}-\tau\right]^{2}}{\sum_{j=1}^{N} \cos ^{2} 2 \pi v t_{j}-\tau}+\frac{\left[\sum_{j=1}^{N} X_{j} \sin 2 \pi v t_{j}-\tau\right]^{2}}{\sum_{j=1}^{N} \sin ^{2} 2 \pi v t_{j}-\tau}\right\}$

Where $\tau$ is defined by the relation:

$\tan 4 \pi v \tau=\left(\sum_{j=1}^{N} \sin 4 \pi v t_{j}\right) /\left(\sum_{j=1}^{N} \cos 4 \pi v t_{j}\right)$

To examine periodicity of different kinds of solar events, Rabiu et al (2007) have used the Fourier transformation by expressing a signal $g$ (t) by a trigonometric Fourier series over any interval of duration $T_{o}$ as:

$g(t)=a_{o}+\sum a_{n} \cos \left(n \omega_{o} t\right)+\sum b_{n} \sin \left(n \omega_{o} t\right)$

Where $n=1$ to infinity and $\omega_{o}=2 \pi / T_{o}$. While $a_{o,} a_{n}$ and $b_{n}$ are the Fourier coefficients.

Monthly data records of maximum temperature (MAT), minimum temperature (MIT), average temperature (AVT), wind speed (WIS), precipitation (RNF), relative humidity (RH), solar radiation intensity (SRA), evaporation (EVA) and sunshine duration (SUD) for the years 1986 -2005 were obtained at five terrestrial stations representing the regional climatic zones under the management of the Kenya Meteorological Department (KMD). Table 1 presents the geographical coordinates of the stations whose data were used in this study.

To investigate the periodicity of the meteorological variables at each station, the Fourier analysis technique was applied to the monthly running means of the meteorological variables and the Scargle's periodograms obtained (Scargle, 1982). Applying a suitable program in MATLAB, the power spectra (periodograms) of the various meteorological parameters at all the stations were obtained.

\section{RESULTS AND DISCUSSION}

The power spectra (periodograms) of the meteorological variables for Kericho station are reported in Figures1 to 9.

The prominent periodicities observed in the periodograms for various variables in the five meteorological stations are reported in Table 2. Table 3 gives the summary of literature reported periodicities of the solar indices and/or solar related activities that are comparable to the modal periodicities of the meteorological variables reported in Table 2.

From Table 2, model periodicities of 6 and 12 months/cycle are observed for all the climatic parameters at all the meteorological stations except Kericho. The modal 6 and 12 months/ cycle for these parameters had been observed by Rabiu et al. (2007). However, a periodicity of 3 months / cycle is also quite prominent for RH, MAT, WIS, RNF and AVT at the stations apart from Kericho.

The prevailing climate in KER can account for their peculiar periods of 50 and 82 months in

Table 1: Geographical coordinates of the meteorological stations

\begin{tabular}{lcccr}
\hline \multicolumn{1}{c}{ Stations (Site) } & Code & Latitude $\left({ }^{\circ} \mathbf{S}\right)$ & Longitude $\left({ }^{\circ} \mathbf{E}\right)$ & Altitude $(\mathbf{m})$ \\
\hline Kericho & KER & 0.4 & 35.3 & 1946.85 \\
Dagoretti (Nairobi) & NBI & 1.3 & 36.8 & 1771.77 \\
Kisumu & KSM & 0.1 & 34.8 & 131.83 \\
Mombasa & MSA & 4.0 & 39.6 & 5.41 \\
Garissa & GRS & 0.5 & 39.6 & 120.13 \\
\hline
\end{tabular}


Figures 1 to 9 depict Power Spectra of Meteorological parameters at Kericho

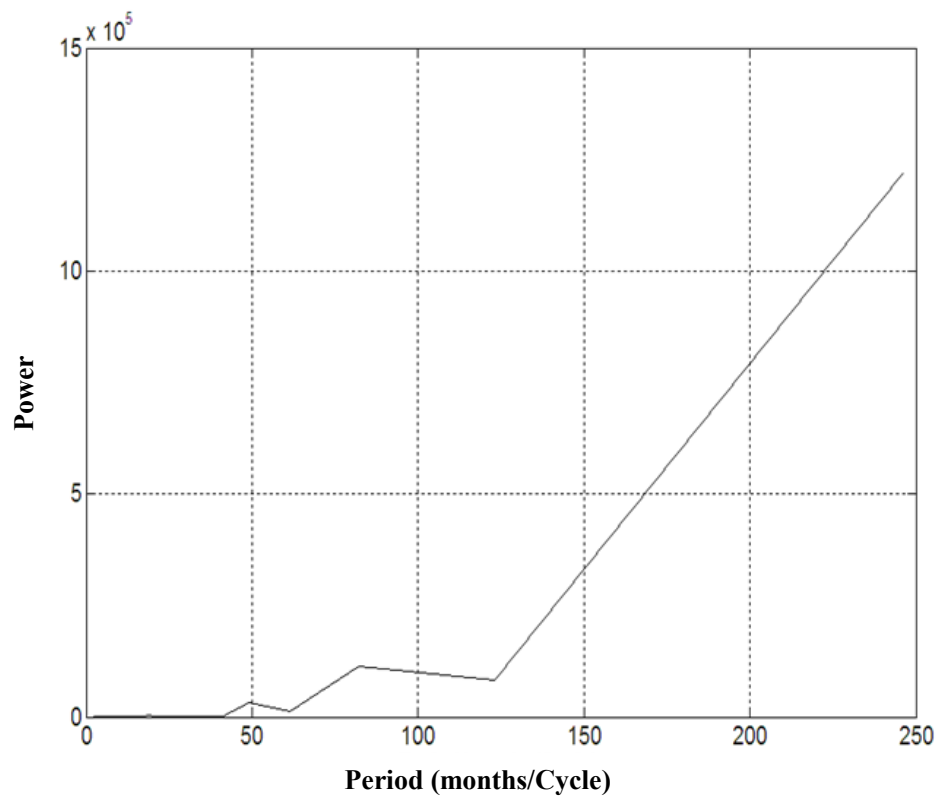

Fig. 1: Periodogram of Relative Humidity at Kericho KER. (The peaks indicate the periods)

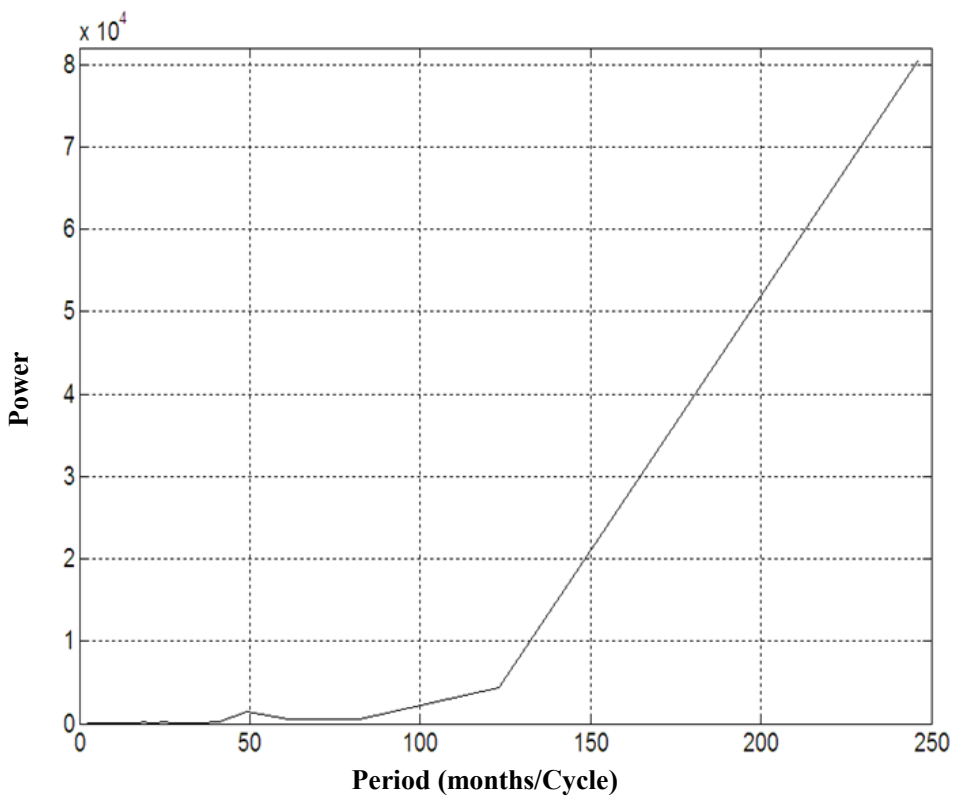

Fig. 2: Periodogram of Maximum Temperature at Kericho KER. (The peaks indicate the periods) 


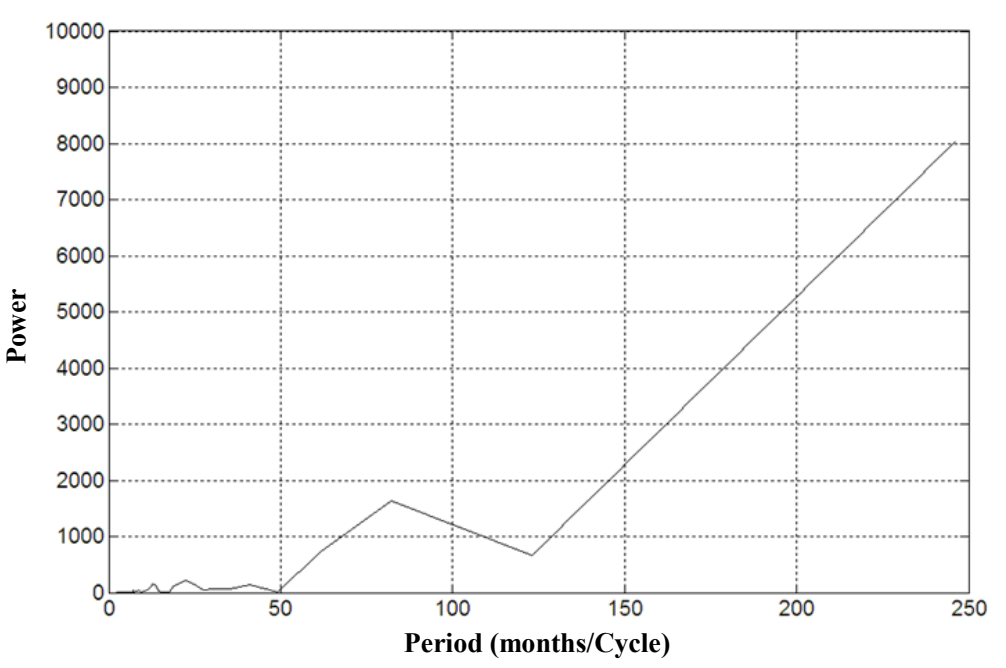

Fig. 3: Periodogram of Minimum Temperature at Kericho KER. (The peaks indicate the periods)

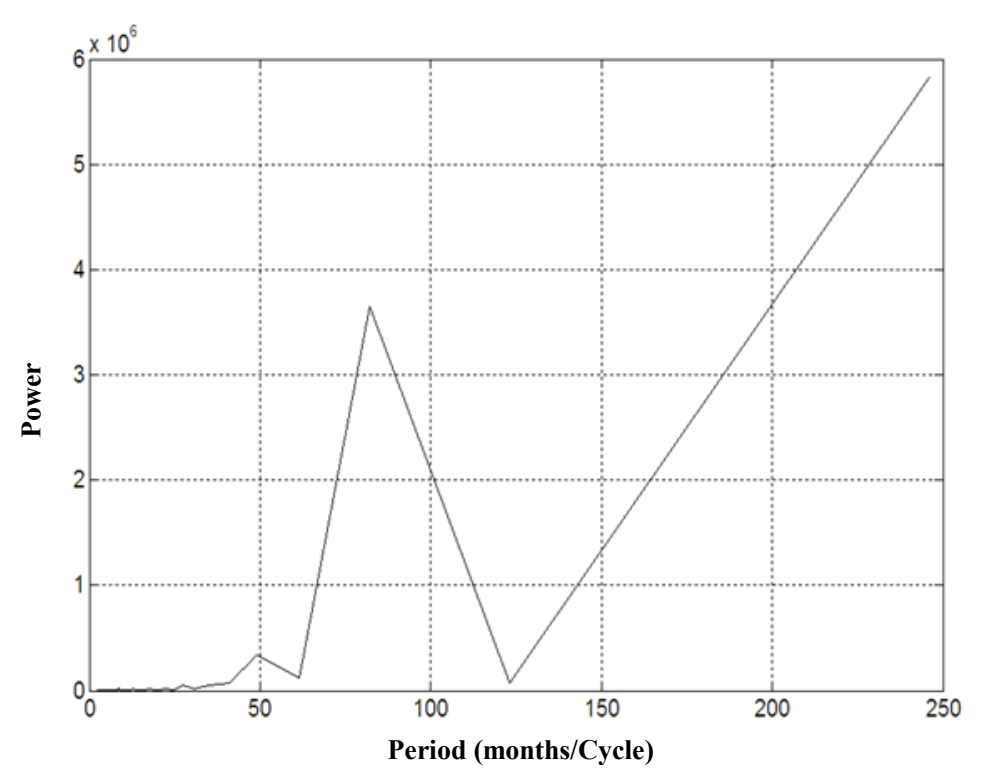

Fig. 4: Periodogram of Wind Speed at Kericho KER. (The peaks indicate the periods) 


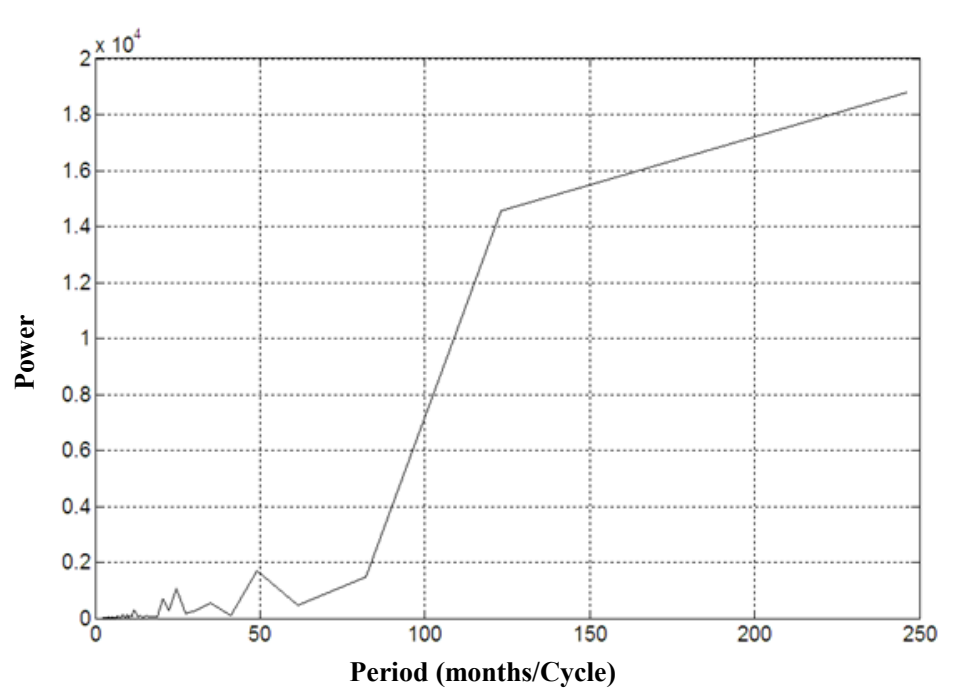

Fig. 5: Periodogram of Sunshine Duration at Kericho KER. (The peaks indicate the periods)

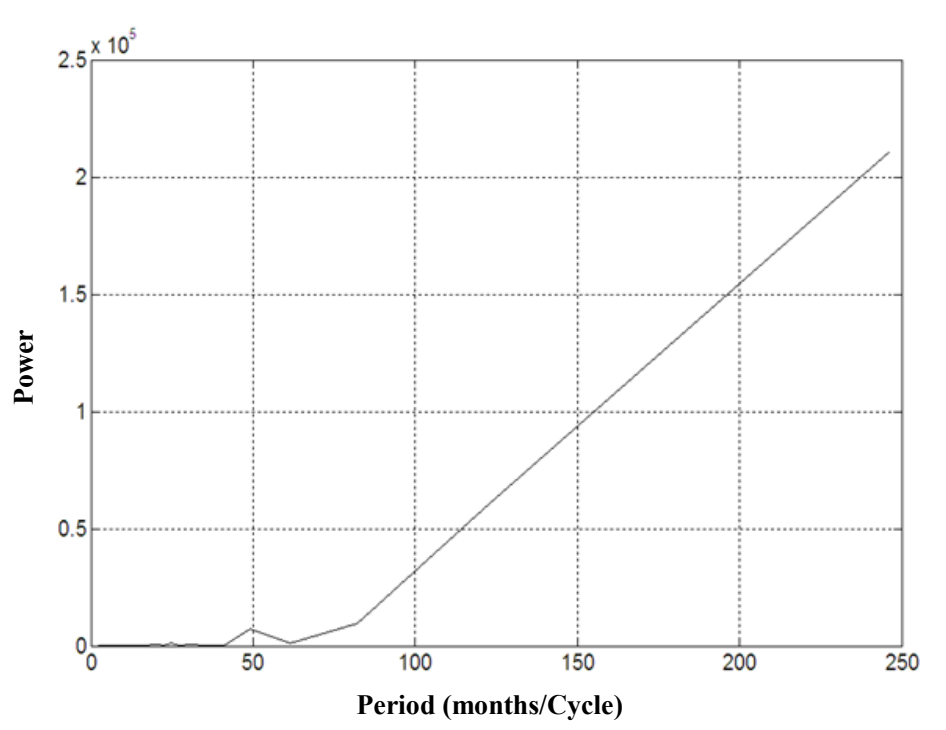

Fig. 6: Periodogram of Solar Radiation Intensity at Kericho KER. (The peaks indicate the periods) 


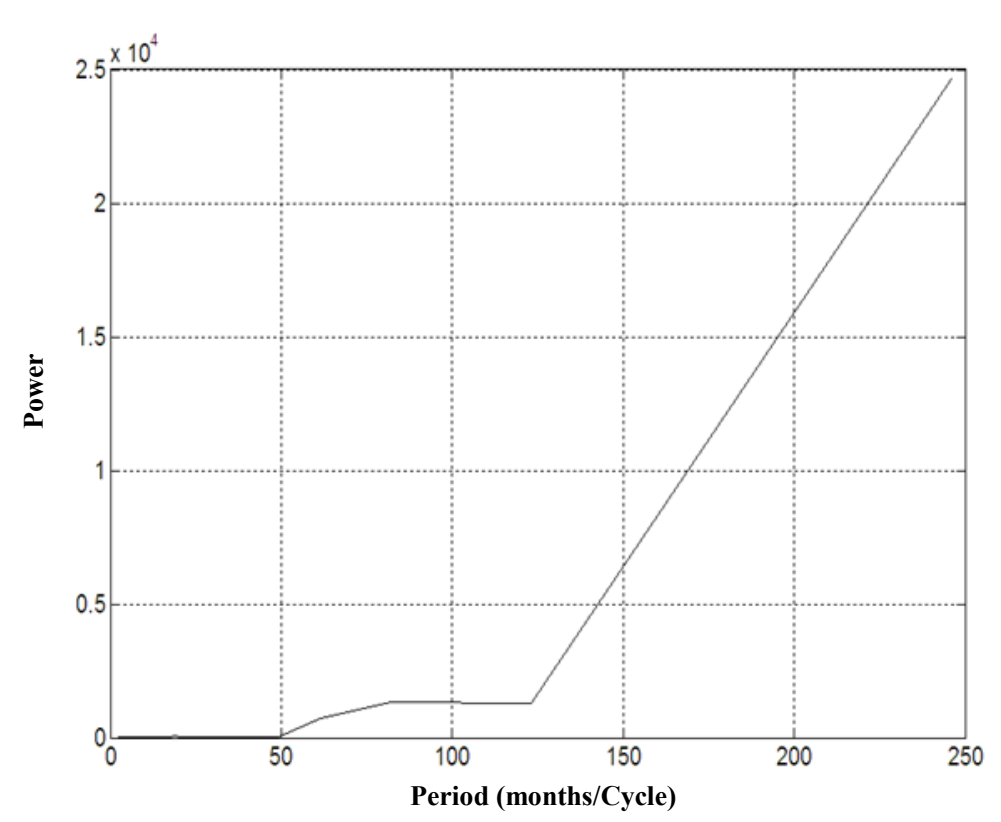

Fig. 7: Periodogram of Evaporation at Kericho KER. (The peaks indicate the periods)

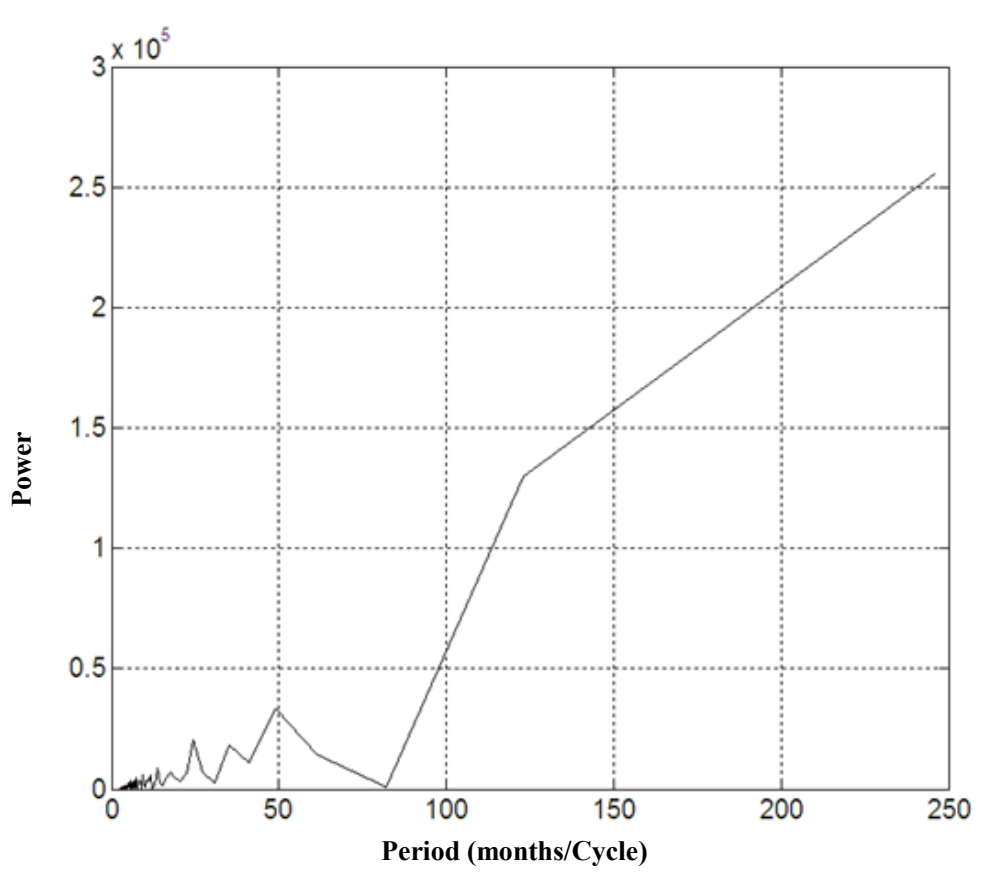

Fig. 8: Periodogram of Rainfall Intensity at Kericho KER. (The peaks indicate the periods)

Journal of Science and Technology @ KNUST December 2009 


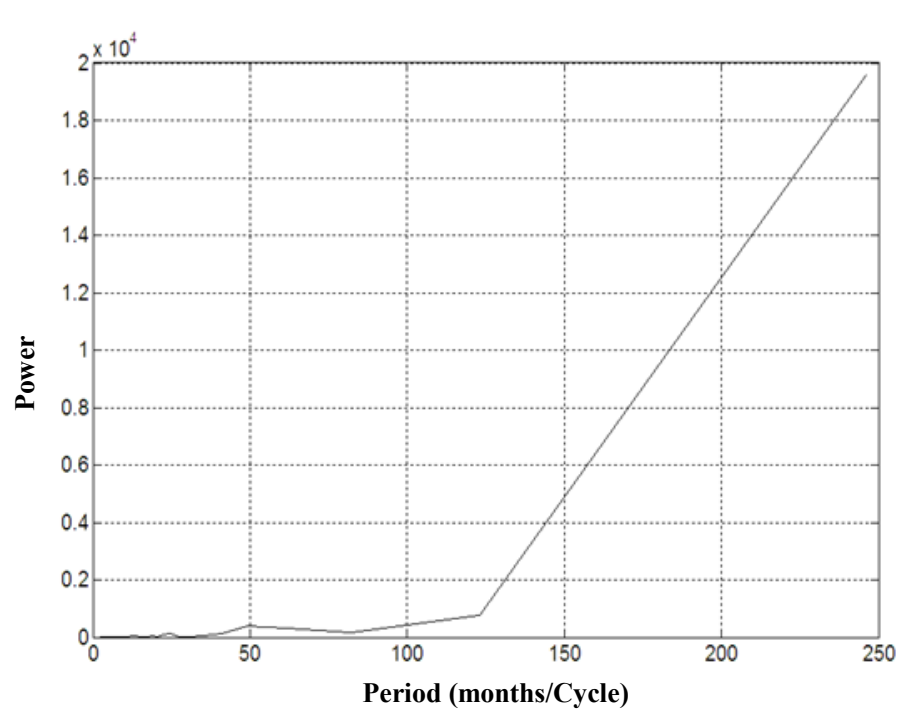

Fig. 9: Periodogram of Average Temperature at Kericho KER. (The peaks indicate the periods)

Table 2: Periodicities in months of different climatic parameters at different stations

\begin{tabular}{|c|c|c|c|c|c|c|}
\hline $\begin{array}{c}\text { Climatic } \\
\text { Parameters }\end{array}$ & NBI & KER & KSM & MSA & GRS & MODE \\
\hline $\mathrm{RH}$ & $5,12,40.5$ & 50,86 & $\begin{array}{l}3,6,12,2236, \\
85\end{array}$ & $\begin{array}{l}3,6,12,36, \\
62,125\end{array}$ & $3,6,12,41,82$ & $3,6,12$ \\
\hline MAT & $4,6,12.5$ & 50 & $3,6,12,36$ & $3,6,12,1635,60$ & $\begin{array}{l}3,6,12,18 \\
27.5,40,122\end{array}$ & $3,6,12$ \\
\hline MIT & $5,12.5$ & 25,86 & $3,6,12,62125$ & $\begin{array}{l}6,11,12,17,22.5 \\
31,50,83\end{array}$ & $3,6,12,18,36$ & 6,12 \\
\hline WIS & $7.5,12$ & 50,82 & $6,12,21,31,61$ & $3,6,12,35,82.5$ & $\begin{array}{l}3,6,12,22,28, \\
62\end{array}$ & $3,6,12$ \\
\hline SUD & 12,35 & 25,50 & $\begin{array}{l}1,6,12,20,25 \\
35,85\end{array}$ & $\begin{array}{l}3,6,7,12,32,36, \\
50\end{array}$ & $\begin{array}{l}3,6,7,12,21, \\
36\end{array}$ & 6,12 \\
\hline SRA & $6,12,50$ & 50 & $3,6,12,81$ & $3,6,12,50$ & $\begin{array}{l}3,5,6,12,32 \\
123\end{array}$ & 6,12 \\
\hline EVA & 6,12 & & $\begin{array}{l}6,12,22,35, \\
82.5\end{array}$ & $3,6,12,80$ & $3,6,12,50,82$ & 6,12 \\
\hline RNF & $3,6,12$ & $25,35,50$ & $3,6,17,20,40$ & $3,6,12$ & $3,4,6,12,50$ & $3,6,12$ \\
\hline AVT & $3,6,7,1225$ & 50 & $3,6,12,82.5$ & $\begin{array}{l}3,5,6,7,12,32, \\
50,82.5\end{array}$ & $2,3,7,37$ & $3,6,12$ \\
\hline
\end{tabular}

Table 3: Periodicities of some solar indices and/or solar related activities

\begin{tabular}{ll}
\hline Periodicity & Solar indices/solar related activities with similar periodicity \\
\hline Semiannual (6 months) & Semiannual effects in atmosphere due to solar activity \\
Annual (12 months) & Annual effects in the atmosphere due to solar activity \\
Quasi-biennial (25 months) & $\begin{array}{l}\text { Sunspot numbers, Solar radio flux } 10.7 \mathrm{~cm} \text {, Green coronal activity index, } \\
\text { Solar neutrino index. }\end{array}$ \\
$\begin{array}{l}10 \text { to } 11 \text { year } \\
\text { (About } 125 \text { months) }\end{array}$ & Sunspot numbers, Solar radio flux $10.7 \mathrm{~cm}, \mathrm{Mg}$ II core-to-wing ratio etc. \\
\hline
\end{tabular}


some of the variables. The region is characterized by mountainous terrain that is rainy, with colder temperature throughout the year (Ogallo, 1989). The kind of climate in KER that is caused by the attendant orography can be the cause of the observed periods.

The 6-month period is a demonstration of semiannual effect in the atmosphere, while the 12month period is a manifestation of the annual effect. The semiannual changes in the atmosphere have been related to solar activity by Russell and McPherron, (1973) and Clua de Gonzalez et al. (2001).

Rabiu (2004) observed semiannual variation in the upper atmosphere and attributed this to the semiannual changes in the ionospheric heating and ionization; the IMF-effect in the solar wind -magnetosphere coupling; favored alignment of the magnetospheric boundary with respect to the solar wind interaction at equinoxes; and equinoctial/semiannual increase in solar wind speed. It is possible that the three separate and independent components, viz. a semiannual, an annual and a Sun-Earth-distance determined component, all of which can be accurately determined from solar-terrestrial geometry alone, (Chaman-Lal 2000), can account for the observed modal periods of 6 - and 12-months. This is an evidence of solar signature on terrestrial climate.

Quasi-biennial periods of 25 months are also seen in Kericho meteorological station for: MIT, SUD and RNF. Georgieva, et al. (2000) have reported that Quasi-biennial oscillation of stratospheric winds (QBO) signals have been identified in a number of geophysical parameters, such as sea level pressure, ozone distribution, Earth's rotation, and that its existence has been shown in solar activity parameters as sunspot numbers, solar radio flux $10.7 \mathrm{~cm}$, green coronal activity and solar neutrino flux.

The 10 to 11 year solar cycle manifests as 125 months periodicity that appears in all the solar indices. The climatic parameters: MAT, SRA, all in GRS show similar periodicity. This is an indication that the semi arid region is prone to solar signature on these climatic parameters. RH in MSA also shows the same periodicity as the solar parameters. The coastal region of MSA registers the highest humidity levels of all the regions. Since RH depends on evaporation that in turn depends on radiation from the sun, it is therefore true that the unique humidity levels in MSA are due to the solar forcing in this region. We also have periodicity of 125 months occurring in KSM for MIT that corresponds to the 10 to 11 year solar cycle.

\section{CONCLUSIONS}

The modal 6 and 12 months (the semiannual and annual) periodicities observed in all the climatic parameters in NBI, KSM, MSA and GRS are due to solar activity forcing.

The Quasi-biennial periodicities of 25 months/ cycle observed in Minimum temperature, Sunshine duration and rainfall in Kericho are due to solar activity whose parameters such as sunspot numbers, solar radio flux $10.7 \mathrm{~cm}$, green coronal activity and solar neutrino flux have also shown Quasi-biennial Oscillation signals.

The 10 to 11 year solar cycle that is evident in all the solar indices, is also observable in MIT and RH for KSM and MSA respectively as 125 months/cycle; it is also close to the 122 and 123 months/cycle for MAT and SRA respectively in GRS. This is a probable evidence of solar control on terrestrial climate.

\section{ACKNOWLEDGEMENT}

Special acknowledgement goes to the Director of the Kenya Meteorological Department, Nairobi for providing the data used in this research. ABR and JKUAT acknowledge the visiting fellowship provided by African Network of Scientific and Technological Institution (ANSTI-UNESCO) during the course of this work.

\section{REFERENCES}

Anderson, R. Y. (1982). Long geoclimatic record from the Permian: Journal of Geophysical Research, 87, p. $7285-7294$. 
Bai, T. (2003). Periodicities in Solar Flare Occurrence: Analysis of Cycles 19-23; ApJ, April 8, 2003.

Bourke, P. (1996). (http://astronomy. swin.edu.au/ pbourke/other/correlate/.). Paper accessed on February 6, 2007.

Campbell, W. H., 1977. Spectral characteristics of geomagnetic field variations at low and equatorial latitudes. Journal of Atmospheric and Terrestrial Physics, 39, 12171227.

Chaman-Lal (2000). Sun-earth geometry, geomagnetic activity, and planetary F2 layer ion density. Part 1: Signatures of magnetic reconnection, Journal of Atmospheric and Solar-Terrestrial Physics, 62, 3-16.

Clua de Gonzalez, A. L., Silbergleit, V. M., Gonzalez, W. D., and Tsurutani, B. T. (2001). Annual variation of geomagnetic activity, Journal of Atmospheric and Solar -Terrestrial Physics, 63, 367-374.

Dean, W. E. (2006). Sun and Climate (http:// greenwood.cr.usgs.gov/pub/fact-sheets/fs0095-00/). Paper accessed on July 30, 2007

Georgieva, K., Tsanev, V. and Kirov, B. (2000). Solar asymmetry, QBO and Climate, In: Proceedings of the SPARC 2000, Second Assembly of the SPARC/WCRP Project. (www.aero.jussieu.fr/Sparc/ SPARC2000new/PosterSess3.html).Paper accessed on October 30, 2007.
Ogallo, U. (1989). The spatial and temporal patterns of the East African rainfall derived from PCA. Inter J. Climatology, 9, 145167.

Rabiu, B. A. Ndeda, J. O. H., Ngoo, L. H. M. and Ouma, G. O. (2007). Spectral Characteristics of the Meteorological Variables over Kenya, East Africa; Proceedings of the International Conference on the Impacts of Exreme Weather and Climate on Socio-Economic Development in Africa. 11-15 November, Akure, Nigeria, 132-135.

Rabiu, B. A. (2004). Semiannual variation of geomagnetic activity Ak index and its response to solar activity. Zuma Journal of Pure and Applied Sciences, ZJPAS, 6. (1). 40-47.

Russell, C. T. and McPherron, R. L. (1973). Semi-annual variation of geomagnetic activity, J. Geophys. Res. 78, 92-108.

Scargle, J. D. (1982). Studies in astronomical time series analysis. II. Statistical aspects of spectral analysis of unevenly spaced data, Astrophys. J., 263, 835 - 853.

Valde's-Galicia, J. F. And Mendoza, A. L., 2005. The solar magnetic flux mid-term periodicities and the solar dynamo. Journal of Atmospheric and Solar-Terrestrial Physics, 67, 1697-1701. 